\title{
e-Parenting Consulting in Early Childhood Institution
}

\author{
Ernie Isis Aisyah Amini ${ }^{1, *}$ Syamsul Mujahidin ${ }^{1}$ Fauziyah Syahrawati ${ }^{1}$ \\ ${ }^{1}$ Pamong Belajar BPPAUD \& DIKMAS NTB, Mataram, Indonesia \\ *Corresponding author. Email: isisamini@yahoo.com
}

\begin{abstract}
e-Parenting Consulting (e-Tingting) is an application developed by Early Childhood Education and Society Education Development Centre of West Nusa Tenggara (BP-PAUD \& Dikmas NTB), Indonesia, in 2018 with the aim of providing services in the form of parenting and online consultation for parents developed based on the Education unit. Through this application, parents are expected to be able to access parenting materials, interact and consult directly with teachers regarding child development from all aspects of development. Each educational institution has its own consulting service that focuses on the parents of each student by involving the teacher at the school as an admin and counsellor. As an application, e-Parenting Consulting has gone through a process of conceptual testing and operational testing in three locations, namely TK N Pembina Labuapi, TK N 3 Gerung and TK IT Anak Sholeh, all located in Indonesia. The success of the application is obtained through the results of measurements of the attractiveness of the model script, the attractiveness of the application, the feasibility of the model and the effectiveness of the model. The e-Parenting Consulting application is expected to be a solution for parents and Early Childhood Education institutions to easily obtain services in the form of parenting materials and consultation anywhere and anytime.
\end{abstract}

Keywords: Electronic parenting, consulting, early childhood institution

\section{INTRODUCTION}

Educating children requires patience and knowledge in order to avoid unwanted attitudes and behavior of children from developing. As the first and foremost educators for children, parents definitely act role models as well as protectors of children. Parents need to master holistic knowledge, especially related to the way to understand the world of children, aspects of children development and methods of conducting parenting.

Parents bring their respective backgrounds and lifestyles in the parenting process. Undeniably, they need to adapt to the new rules of the current world development to keep themselves engage in quality communication with their children. A parent and child interaction are required because children learn from a variety of interactions that they have with their parents. Parke and Buriel (2007) stated that parents have certain expectations in the process of interaction to build the socialization and growth of their children which are summarized in three ways, firstly as an interactive partner with their children, secondly as an instructor or teacher who directly guides their children, and thirdly, as a support that complement the needs in stimulating children's growth.

Consequently, it is necessary for parents to increase their knowledge and insight about positive parenting towards children. In this circumstance, they need to be "parents of the present age", which is also supported by positive parenting. Nowadays the source of knowledge can be easily accessed through technology media, for example through the use of media, both offline and online, there is no longer a reason for parents to refuse to study because it is difficult to manage their time or due to busy working schedules etc. In the Early Childhood Education institutions (ECE), efforts to deliver knowledge and insights related to parenting to parents have been carried out through direct meetings in activities that are incidental. In this sense, the educational institution has not made the activity as an important program and scheduled it regularly. Based on an exploratory study, there are several reasons for this occurrence, such as a) The manager does not understand the essential meaning of parenting activities, b) The manager does not have material related to parenting, and c) The manager does not understand the strategy and method of implementing parenting. Related to the parenting activities, some facts found are a) Parenting activities is held conventionally through face-to-face and not regularly scheduled, b) Parent's knowledge of early childhood development is still low, c) The rate of parents' attendance in participating in parenting activities in schools are still low, and d) Parents have not optimized the use of information media and technology to increase knowledge about childcare (BPPAUD DIKMAS NTB, 2018). Based on this data, it is necessary for ECE to have a program that provides services for parents to have a professional consultation related to parenting to address a variety of concerns and problems faced in parenting. 


\section{FRAMEWORK}

\subsection{Early Childhood}

Early childhood is a period for children with an age range of 0-6 years. This period is well known as a golden age which represents a time when a child's brain develops most rapidly throughout their life. The brain is the main key in the formation of children's intelligence. At this moment, the growth of children' brain development reaches $80 \%$, while the remaining $20 \%$ will develop when they are adults. That is why Montessori said that the brains of golden age children are like sponges that are ready to absorb whatever information they obtain, although, in some ways, children are often not perfect enough in presenting their abilities (Suyadi, 2010).

\subsection{Importance of Parent Involvement in Early Childhood Education}

The family is the first and main place of education for children. They are in the family from the womb until the wedding. Therefore, the role of the family is very important in a child's journey. Home environment, especially parents become very important as a "nursery" of seeds that will grow and develop further. Parenting in early childhood is certainly different from that in children or teenagers who are at school. At this age, children are often referred to as the golden age. These periods are critical periods in which a child needs the right stimuli to achieve perfect maturity. A father and mother are given a gift by God in the form of instincts as parents. Because of this instinct, parents' love for their children arises, so that both morally have a responsibility to take care, supervise, protect and guide their children. A child will grow well if he gets a good education informally. Education in the family is obtained by children from the education provided by parents.

\subsection{Forms of Parent Involvement at School and Home}

Epstein revealed that there are six forms of partnership with parents, namely: parenting, communication, volunteering, involving parents in children's learning at home, decision making, and collaboration with community groups (Coleman, 2013). The following is the explanation of each form of partnership.

1) Parenting: Parenting is an activity to help families understand children's development, appropriate parenting skills, home conditions that support children's learning and help schools obtain information about children. The form of parenting activities can be in the form of participating in workshops that introduce school policies, procedures, and programs to help parents know what is happening at school and how to provide care and education for children.

2) Communication: Communication is an effective form from school to home and home to school to inform about school programs and the progress of children's development. Communication is carried out in order to exchange information between the school and parents.

3) Volunteer: Volunteering is an activity to increase recruitment and organizing parents with the aim of helping and supporting the school program where their children are studying.

4) Parental involvement in children's learning at home: Within the context of this partnership form, schools can provide various information and ideas for parents about how to help children learn at home in accordance with the material learned at school so that there is a continuous process of learning from school to home.

5) Decision-making: Decision making is an activity to collect parents' voices in making decisions about school policies and practices (Hodgkinson, 2010).

6) Collaboration with community groups: This collaboration is carried out by involving representatives of companies, religious groups, communities, and others who can provide experience in children's education (Hodgkinson, 2010).

\section{4. e-Parenting Consulting}

e-Parenting Consulting is an application that provides services in the form of parenting material and online consultations for parents that are developed based on the Education unit. Parents can access information about positive parenting through simple materials that are easily accessed by users (teachers and parents). It also includes consulting services that can be used for interactions between educators and parents.

Making children comfortable in the education process is crucial because the world of early childhood is a world full of joy, warm and cheerful. All activities aimed at early childhood should always give birth to comfort. Margolin (1982) emphasizes that when interacting with children, create an atmosphere that is attentive and pleasant, focusing on the goals of the child's needs. In order to achieve those intentions, e-Parenting Consulting could be used to obtain various tips and simple solutions. Thus, the treatment provided by the educators at school and parents at home can be in-line. 


\subsection{The Role of Parents in e-Parenting Consulting}

Parenting is a process in which both parties change one another as the child grows into an adult figure. Parental involvement is mental participation accompanied by contributions and responsibilities. This includes several activities namely: protecting children, providing housing or shelter, clothing, food, caring for children (including bathing, teaching how to defecate, and caring for when a child is sick), providing affection and attention to children, interacting with children and providing stimulation to him, and providing the ability to socialize with his culture. Thus, parenting is taking responsibilities of and nurturing children in daily life, both physical and non-physical and conducted directly and indirectly.

The challenge of parenting today is more dynamic than a few years ago because of technological and information advancements. Technological advancements cause enormous changes in human life with all civilizations and cultures. This change has a profound impact on the transformation of values in Indonesia. At present, in Indonesia, we can see the great influence of technological progress on the transformation of values in society, especially people with eastern cultures both in rural and urban communities, namely the era of modernization.

Giving understanding to the parents related to the challenges of parenting is very important so that parents can be aware of the thing that should and should not be done. Parents are expected to be able to help and support children through guidance, direction and motivation and other educational behavior. Parents need parenting knowledge and skills that can be obtained through e-Parenting consulting application. Some materials that are considered important such as creating a pleasant home learning environment, establishing communication and interactions that are warm and loving, providing motivation and instilling confidence in children, and disciplining children. The material in e-parenting consulting will be packaged interestingly, concisely and clearly accompanied by interesting and educational images.

\section{DISCUSSION}

In general, the description of e-Parenting Consulting Applications is as follows:

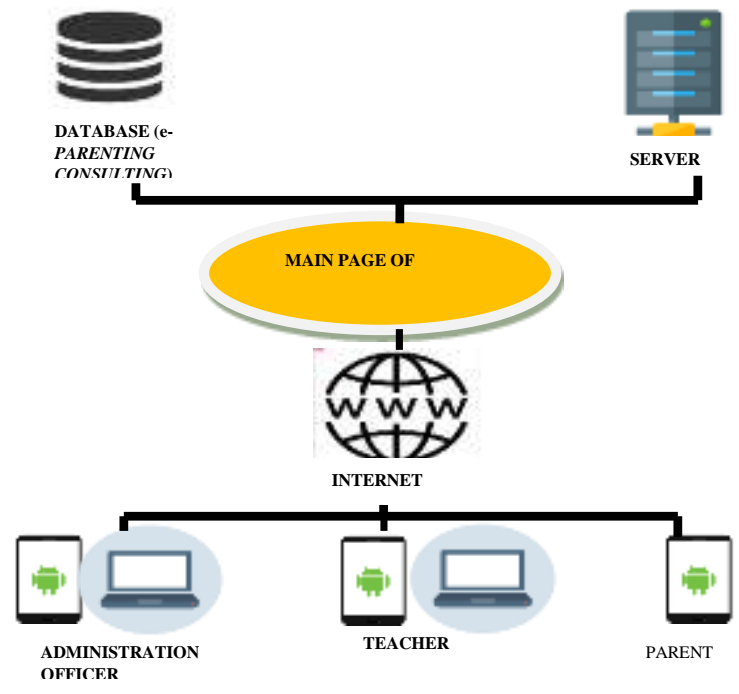

Figure 1 General overview of e-parenting consulting applications

The e-Parenting Consulting system was built using the concept of the internet, which contains databases and applications. It provides access to e-Parenting Consulting pages containing parenting material and online consulting services for parents.

This application can be accessed using a smartphoneandroid system. The application can be easily accessed and downloaded via Google Playstore. In the e-Parenting Consulting application, there are 4 main users identified, namely the administrator who is the main manager of this system from the Balai Team, the IT Team who helps in the preparation of the e-Parenting Consulting Application, ECE Teachers in addition to being a user as well as an administrator who has a user account, and parents as service users. In its implementation, e-Parenting Consulting will provide Parenting material compiled by the Balai Team and provided services in the form of online consultations for parents that will be handled by teachers in the Education unit who have followed the Technical Orientation for consultation

The e-Parenting Consulting model is an alternative to parenting media in the form of an online application that can be utilized by the Early Childhood Education institution, in organizing parenting. It has been tested in three selected ECE units in accordance with the model's requirements. The three ECE units are TK Pembina Labuapi, TKN 3 Gerung and TK IT Anak Sholeh Lembar.

The same treatment is given at those three locations of the operational experiment, namely conducting technical orientation related to the model, guiding and assisting in the implementation of the model and measuring the attractiveness of the model, the feasibility of the model and the effectiveness of the model. In addition to measurements, the development team tested the attractiveness of the 
application as a product model, to find out how attractive the application was used as a parenting media and also to determine weaknesses or obstacles in implementing the application model.

The e-Parenting Consulting is abbreviated as e-Tingting, in order to ease users to search, download and make it as parenting media. The e-Tingting application is quite small in size, which is $4.2 \mathrm{MB}$ and can be downloaded via Play Store.

The results of the experiment in three locations show that the model and application scripts in terms of attractiveness reached the average value in the range of $74.67 \leq \square<93.33$, which means it is quite interesting for ECE units to make it an alternative organizing parenting. The attractiveness of the application is also in the range of $34.67 \leq \square<43.33$, which means that this application is quite interesting as a media for parenting in ECE units.

In terms of the feasibility of the model, the three PAUD units were also measured. In each trial location, the development team measured 20 respondents comprises the principal, teachers, administrative staff and parents of students. The model's feasibility test also showed pretty good results, which were within the mean ideal criteria and ideal standard deviation of $55 \leq \square<65$, which means that this model was easy to implement as an alternative to implementing parenting in ECE units.

The analysis for the effectiveness of the model shows that the $t$ arithmetic is greater than $t$ table at a significance level of $5 \%$, meaning that it indicates a significant increase of the post-test compared to the pre-test. By comparing the value of t-arithmetic and t-table, the results show that $\mathrm{t}$-arithmetic of -11,799 in TKN Labuapi, -7,816 in TKN 3 Gerung and 8,838 in TKIT Anak Sholeh Lembar. All of those are bigger than t-table $(-2,093)$. As for using the formula Sig. (2tailed) $>0.05$, the data obtained shows that the significance value of 0.000 is smaller than 0.05 . It is then concluded that there was an increase in the average value of the pre-test and post-test after treatment, and the increase was significant. Using e-Tingting as a parenting media is likely to cause changes in attitudes, perspectives, and parental behavior of parents for early childhood. It also regarded as an effective tool for ECE institutions to communicate and interact with parents. e-Tingting application is believed to be able to foster positive inspiration for early childhood education institutions and parents in stimulating early childhood development.

There are some obstacles faced by researchers in conducting the experiment, such as:

\subsection{Tools}

1) Tools that do not support the application: The (Mobile) tool used by the user does not support the user to use the application. The e-Tingting application is designed for android users with a KitKat installed. There are some users with Android who do not meet these qualifications. Thus, even though the application has been downloaded, the application cannot be opened or often stops working in the middle of usage.

2) Limited internet access: The e-Tingting application is an online application that can only be accessed if the user is connected to the internet, either through the use of WIFI or a personal data package. This then becomes the hinder for some respondents to access the application.

\subsection{Human Resources in Relation to The Community Mindset}

It is quite general to find that humans have tendencies to have difficulties in accepting changes and need time to move from the old system to the new system. Several reasons are provided:

1) The inability to look forward

2) The lack of focus

3) Feeling threatened and discomfort

4) The laziness to update knowledge.

\subsection{Application System}

There are a few things that need to be taken into account: 1) The search feature does not work properly. Users must write the full name of the school to find the school in question. Supposedly, by merely typing "TK", all of the names of the TK institutions in NTB will appear

2) The application suddenly stopped in its use.

Some of the points above are important to be considered for improving the application of the e-Parenting consulting in the future. Therefore, the e-Parenting consulting model can be utilized for providing better parenting practices needed.

\section{CONCLUSION}

The model is conducted according to the Directorate General Regulation No. 2 of 2016 on Technical Guidelines for the Development of Early Childhood Education Models and Community Education, namely development proposal, preliminary studies, draft model' preparation, validation of draft models, conceptual experiment, operational experiment, standardization, dissemination, implementation and reflection.

Suggestions and input through focus group discussions and seminars enriched the final product development. Each stage contributes to changing the draft model to the final product in the form of a model. Therefore, it can be said that the e-Parenting consulting is a product which aims to answer the faced problem of the implementation of parenting activities in ECE institutions. Moreover, online- 
based models in the form of e-Tingting applications is considered as an answer to what kind of media that can be used as parenting media in ECE units.

The success of e-Parenting Consulting in its implementation was obtained through the operational experiment conducted in three locations, namely TKN Pembina Labuapi, TKN 3 Gerung and TK IT Anak Sholeh Lembar. The success of the model is gained from the results of measurements of the attractiveness of the model script, the attractiveness of the application, the feasibility of the model and the effectiveness of the model.

\section{ACKNOWLEDGMENT}

The authors would like to thank BP PAUD \&

Dikmas NTB, Indonesia, for supporting the development of e-Parenting Consulting application and funding the entire research process

\section{REFERENCES}

BPPAUD \& DIKMAS NTB. (2018). Laporan study pendahuluan pengembangan model PAUD. Mataram: BPPAUD \& DIKMAS NTB

Coleman, M. (2013). Empowering family-teacher partnership building connections within diverse communities. Los Angeles: Sage Publication.

Hodgkinson, K. W. (2010). Parental involvement and assistant principal efficacy. Retrieved from www.Proquest.com on 7 February 2018.

Margolin, G. (1982). Ethical and legal considerations in marital and family therapy. American Psychologist, 37(7), 788.

Parke, R. D., \& Buriel, R. (2007). Socialization in the family: Ethnic and ecological perspectives. Handbook of child psychology, 3 .

Suyadi. (2010). Psikologi belajar PAUD. Jogjakarta: Pedagogia 